\title{
Renda da terra e capitalização em David Harvey. Notas sobre o caráter especulativo da propriedade imobiliária
}

Land rent and capitalization from David Harvey. Notes on the speculative profile of immovable property

Rente de la terre et capitalisation selon David Harvey. Notes sur le caractère spéculatif de la propriété immobilière

Renta de la tierra y capitalización según David Harvey. Anotaciones sobre el carácter especulativo de la propiedad inmueble

\section{Maurilio Lima Botelho}

\section{(2) OpenEdition}

Journals

Edição electrónica

URL: http://journals.openedition.org/espacoeconomia/2273

DOI: $10.4000 /$ espacoeconomia.2273

ISSN: 2317-7837

Editora

Núcleo de Pesquisa Espaço \& Economia

Refêrencia eletrónica

Maurilio Lima Botelho, "Renda da terra e capitalização em David Harvey. Notas sobre o caráter especulativo da propriedade imobiliária », Espaço e Economia [Online], 8 | 2016, posto online no dia 17 outubro 2016, consultado o 30 abril 2019. URL : http://journals.openedition.org/ espacoeconomia/2273; DOI : 10.4000/espacoeconomia.2273

Este documento foi criado de forma automática no dia 30 Abril 2019.

(c) NUPEE 


\section{Renda da terra e capitalização em David Harvey. Notas sobre o caráter especulativo da propriedade imobiliária}

Land rent and capitalization from David Harvey. Notes on the speculative profile of immovable property

Rente de la terre et capitalisation selon David Harvey. Notes sur le caractère spéculatif de la propriété immobilière

Renta de la tierra y capitalización según David Harvey. Anotaciones sobre el carácter especulativo de la propiedad inmueble

\section{Maurilio Lima Botelho}

\section{Considerações introdutórias}

1 A teoria da renda da terra teve uma grande repercussão em determinado momento da teoria social. Entre as décadas de 1960 e 1970, a teoria serviu de base para uma compreensão dos fundamentos sociais da estrutura agrária, assim com sua variante na teoria urbana, a renda do solo urbano, foi de importância para explicar a distribuição de investimentos ou mesmo os padrões espaciais e a divisão funcional de atividades nas cidades. Entretanto, desde a virada cultural na teoria social contemporânea (cultural turn), a teoria da renda da terra foi esquecida ou mesmo contestada como explicação economicista das relações sociais. Relegada ao quarto de despejo da história intelectual, essa teoria foi pretensamente superada por abordagens culturalistas que ressaltam a apropriação subjetiva dos espaços, o relacionamento identitário dos grupos sociais com suas bases físico-territoriais, enfatizam as "comunidades rurais" ou as "tribos urbanas" e suas múltiplas formas de representar seus espaços socialmente produzidos.

Essa trajetória não é diferente no caso brasileiro, embora aqui a teoria da renda tenha passado por uma sobrevida na década de 1990, quando nos países centrais o culturalismo 
já funcionava a todo vapor com sua máquina de desclassificação da teoria crítica radical. O fato se explica pela importância que assumiu os movimentos sociais no campo, particularmente o Movimento dos Trabalhadores Sem-Terra, que protagonizaram ocupações de latifúndios, gigantescas manifestações, sofreram com a repressão e receberam a adesão intelectual num momento em que o neoliberalismo se impunha. Entretanto, a virada do milênio consolidou de vez a teoria culturalista, de modo que mesmo nos cursos básicos em que se ensina geografia, sociologia agrária ou antropologia rural raramente se fala de renda da terra. Mais grave que por aqui a teoria da renda do solo urbano nunca tenha alcançado a importância de sua meia-irmã rural e a maioria dos estudiosos da questão urbana torça o nariz quando se fala em renda absoluta ou diferencial.

O esquecimento tem, em parte, explicação interna e não decorre apenas da desproporcional medição de forças políticas por trás da disputa teórica contemporânea. Na maioria dos casos, a discussão sobre a renda da terra ocorreu através de uma exegese dogmática de textos clássicos (Ricardo, Marx, Lênin) e isso levou a um esgotamento do próprio discurso, que não conseguia enxergar para além dos aspectos esquemáticos mais básicos e não determinava historicamente a teoria, por isso era incapaz de reformulá-la para os novos tempos. Isso produziu uma série de obstáculos, principalmente na difícil mediação da teoria com a empiria. No fundo, o que se viu foi uma formulação que não conseguia enxergar os processos sociais por trás das categorias econômicas. As formas sociais foram esterilizadas diante de conteúdos meramente econômicos, como se os processos sociais girassem sempre em torno de interesses - a própria estrutura social se convertia em fundamento fixo sob o qual os agentes atuavam determinados por suas vontades imediatas. Antes de servir de explicação crítica para o estreitamento do horizonte social burguês, a teoria era derivada da luta entre as classes. Até mesmo os fundamentos históricos das formas da renda ficaram apagados diante do esquematismo: a incompreensão básica da forma social capitalista em suas especificidades históricas incomparáveis acabava por fortalecer o esquema dos "modos de produção", onde vários tipos de renda se fizeram presente antes do capitalismo. ${ }^{1}$ As categorias básicas da socialização capitalista, a forma através do qual necessariamente se desenvolve a teoria da renda - partindo do valor, mercadoria, dinheiro -, ficava encoberta sob o esquema da troca de produtos e da prestação de tributos (válido quase universalmente). Uma teoria crítica radical da forma capitalista e do caráter fetichista das próprias categorias econômicas, era necessariamente uma impossibilidade quando se tratava a renda da terra nesses termos, sem compreender o caráter reificado do mundo burguês - portanto, sem compreensão do economicismo real em que as relações sociais são objetivamente achatadas.

4 A recuperação da teoria da renda da terra, portanto, exige a sua mediação com a compreensão dos processos sociais e da reificação dessas relações em objetos autonomizados. Isso poucas vezes foi elaborado na teoria crítica do capitalismo. Mas há uma contribuição fundamental, um primeiro esboço, desenvolvido por David Harvey em sua obra mais importante, $O$ s Limites do Capital. ${ }^{2} \mathrm{O}$ capítulo sobre a renda da terra não apenas é a melhor parte de toda essa obra como contém uma abordagem nova e radical do papel da propriedade imobiliária na sociedade burguesa. Longe de encarar as formas que assumem a renda como uma versão superior de antigas relações de exploração, aí a renda da terra aparece como uma necessária forma de capital fictício. Trata-se de uma demonstração de que as categorias que envolvem os rendimentos derivados da 
propriedade imobiliária não são meras recuperações internas, no capitalismo, de formas de propriedade anteriores (a propriedade fundiária). Na verdade, a propriedade imobiliária, através da renda, é expressão mais acabada do capital fictício. Como isso só pode ser compreendido a partir da própria forma monetária que é a base de todas as relações sociais modernas, o desenvolvimento de uma teoria da renda nos seus aspectos mais críticos precisa levar em conta as particularidades históricas da sociedade burguesa, principalmente a sua natureza de economia monetária.

David Harvey desenvolveu essa teoria no início da década de 1980 (o livro teve sua primeira edição em 1982), por isso a sua obra foi alvo de um profundo silêncio, já que o contexto em que apareceu era o de um declínio do marxismo. Isso impediu o reconhecimento dessa contribuição fundamental exposta no capítulo XI. No texto que segue pretendemos explorar essa compreensão inusitada da teoria da renda da terra por parte de Harvey - no sentido original de uma formulação que produz estranhamento, pois se opõe ao que é usualmente esperado. 0 núcleo radical de sua teoria não é abalado por algumas dificuldades parciais que o geógrafo escocês enfrenta - principalmente nos pressupostos teóricos de sua teoria do dinheiro. Por isso nossas considerações a seguir não deixam de apontar para alguns desses contratempos, momento necessário de uma reconstrução crítica da teoria da renda. Na verdade, nossa pretensão é mostrar que, apesar de alguns embaraços, a teoria da renda da terra de David Harvey é uma das mais ricas para compreender a sociedade contemporânea, em que a crise estrutural leva o capitalismo a mobilizar ferramentas de ficcionalização da riqueza cada vez mais sofisticadas e destrutivas, no centro do qual se encontra a propriedade imobiliária.

\section{Teoria da renda: entre o monopólio e a concorrência}

6 A renda fundiária decorre do caráter especial e restrito da propriedade privada, isto é, de seu aspecto intrinsecamente monopolista. A propriedade de uma porção da superfície terrestre por determinado indivíduo lhe garante direitos de uso que são exclusivos. Dado que um indivíduo passa a ser dono de uma porção da Terra, então o uso dessa parcela por parte de outros indivíduos se torna passível de cobrança. É possível cobrar pela alienação periódica dessa propriedade (uma espécie de aluguel) ou pela alienação integral e definitiva (a venda e transferência da propriedade privada). Evidente que isso somente decorre da escassez dessa propriedade, por isso a história inicial da sociedade burguesa, sua base histórica, é a concentração das terras, seu cercamento e privatização: a abundância natural de terrenos disponíveis para uso comum inviabilizaria a própria renda fundiária. Ninguém pagaria pelo uso de terrenos que são propriedades alheias se ao lado estivessem disponíveis terras desprovidas de dono. ${ }^{3}$

7 A renda decorre, portanto, desse caráter exclusivo da propriedade imobiliária. É prerrogativa do proprietário exigir um pagamento daqueles que necessitam da terra para alguma atividade produtiva. Repetindo: se o uso for temporário, o proprietário cede a terra em arrendamento pela sua exploração provisória, recebendo para isso a renda do seu arrendatário. Se o uso for definitivo ou exigir um longo período, o proprietário vende a terra, integralizando de vez toda a renda. Em ambos ocorre uma cobrança diante de um direito de uso futuro da propriedade, renda se torna participação nos lucros que podem ser obtidos naquele imóvel. ${ }^{4}$

8 A forma básica da renda fundiária, portanto, decorre desse caráter exclusivo da propriedade imobiliária e ao mesmo tempo de sua natureza indispensável para a 
atividade econômica. A terra, como superfície (o espaço absoluto da física newtoniana), é base ou fundamento de toda e qualquer atividade produtiva. Qualquer um que queira fazer uso de determinada fração da superfície terrestre, seja para uma atividade agrícola, seja para uma atividade industrial ou para a instalação de um mero empreendimento comercial, precisa pagar pelo usufruto dessa porção. ${ }^{5} \mathrm{~A}$ interdição do acesso à propriedade imobiliária impõe, aos que dela necessitam, que paguem pelo seu uso. Decorre daí a renda fundiária absoluta: o pagamento inevitável e necessário à exploração de um imóvel. Que uma propriedade seja maior do que outra, mais comprida ou mais larga, não muda em nada a obrigação do pagamento, só faz o proprietário auferir uma renda proporcional ao seu tamanho, maior ou menor que outra em condições idênticas.

9 Entretanto, as diversas frações da superfície da Terra não são idênticas e as atividades econômicas e produtivas não ocorrem num espaço abstrato e sempre igual. Os imóveis podem ter propriedades diferenciadas e localização distinta. Isso significa, por exemplo, que um solo de qualidade melhor pode representar a obtenção de rendas mais elevadas para o seu proprietário do que um outro com atributos piores. Assim, no campo, uma terra pode ser mais fértil do que outra, o que sem dúvida terá implicações sobre a produtividade de alimentos. Na cidade, um terreno plano pode oferecer facilidades na construção de uma casa frente a outro em declive, que exigiria um trabalho prévio de terraplanagem. Além disso, uma propriedade próxima de uma cidade pode significar acesso rápido ao mercado consumidor e aos fornecedores, comparativamente a outro terreno bem mais afastado. Decorre dessas diferentes características entre os imóveis que seus donos podem obter rendas mais elevadas ao lançá-las no mercado. A renda extra auferida pelos proprietários de melhores terras diante da renda dos demais é chamada de renda diferencial, cuja variação depende do conjunto de aspectos distintos que apresenta aos seus arrendatários. Nesse caso, a renda é maior porque pode representar ganhos mais elevados para os que utilizam a propriedade de modo produtivo: trata-se da apropriação de parte do sobrelucro oferecido pelas qualidades daquele imóvel. ${ }^{6}$

10 Há um terceiro tipo de renda - na verdade, uma forma especial da renda diferencial - em que não se trata de uma diferença que se possa ser estabelecida na comparação direta entre terrenos. A renda decorre do caráter absolutamente incomparável de uma determinada propriedade. Assim, guardados alguns pré-requisitos, pode-se produzir vinhos num número incalculável de lugares, sobre terrenos e solos variados. Entretanto, a produção de autênticos vinhos Bourdeux e Champanhe só pode ser feita nas respectivas regiões da França, onde uma qualidade específica de solo e uma prática já secular de produção o tornam incomparáveis. Aqui temos um caso de renda de monopólio: a particularidade do imóvel é tamanha que há uma arbitrariedade na determinação de sua renda. Como não há concorrência ou ela é muito reduzida, a renda auferida nesses terrenos é elevadíssima. As obras de arte também seguem esse critério: qualquer um pode pintar uma paisagem bucólica de banhistas à beira de um rio, mas apenas um quadro de Monet pode alcançar milhões no mercado de arte. $\mathrm{O}$ monopólio aqui se refere à originalidade e consagração dos traços do pintor, reconhecido internacionalmente.

11 Tradicionalmente utilizada para o caso do campo e para a arte, a renda de monopólio pode ser aplicada também às cidades: apartamentos em frente ao Central Park ou imóveis com vista para a Torre Eiffel obtém renda incomparável a outros em virtude do caráter raro de sua situação. David Harvey é sem dúvida o autor que mais profundamente desenvolveu as implicações da renda de monopólio para a teoria urbana, particularmente os vínculos que essa oferece entre economia e cultura. ${ }^{7}$ Em síntese: enquanto a renda de 
monopólio é o resultado de uma condição a princípio irreproduzível de uma propriedade, a renda diferencial deriva de uma relação entre propriedades imobiliárias e a renda absoluta advém da propriedade tomada em si mesma.

Há, portanto, um escalonamento que nos leva da renda fundiária absoluta até a renda diferencial e o caso especial da renda de monopólio. A renda absoluta pode parecer como o fundamento sobre o qual se ergue todas as demais e, tomado como esse ponto de partida, a renda mínima obtida pela pior propriedade disponível no mercado: como não tem nada de diferencial que a torne mais vantajosa, o preço que se paga pelo seu uso é o mínimo básico de renda que qualquer proprietário pode auferir de seu imóvel. É óbvio que a pior propriedade disponível pode ser variável, dependendo de como avança ou retrai o mercado: se um determinado imóvel deixa de ser útil e não obtém nenhum interessado em seu uso, então é o terreno seguinte, em condições imediatamente um pouco melhores, que passa a ser agora a base sobre a qual se assentam os arrendamentos. Entretanto, a renda absoluta não é a raiz das demais, mas ela mesma é uma renda que só pode existir em determinadas condições históricas em que a concorrência e a produtividade estão limitadas.

13 Os parâmetros históricos comparecem de forma determinante sobre a teoria da renda fundiária, pois estamos distantes das condições em que Marx escreveu sobre o tema, assim como ele próprio já se distanciava da experiência de Smith e Ricardo. Essa contextualização impõe marcas à teoria da renda, uma delas é a pressuposição por parte de Marx de que necessariamente, no caso da agricultura, a oferta de alimentos deve se tornar idêntica à demanda. Esse pressuposto tem certa importância lógica, na medida em que permite compreender o papel das piores terras e sem nenhum diferencial - portanto, instrumento heurístico para explicar a função da renda absoluta. Diante de uma necessidade de produzir para um mercado ainda não satisfeito, então o capital deve se defrontar com os limites impostos pelos proprietários de terras e aceitar partilhar seu lucro - e renda nada mais é do que a absorção de parte das mais-valia produzida. 0 poder capitalista precisa se contrapor ao poder dos proprietários fundiários em virtude da necessidade de terras, mesmo as que possuem as piores condições para a produção. Contudo, essa pressuposição tem implicações críticas que não podemos desenvolver aqui, pois hoje, em pleno século XXI, conhecida toda a história de superprodução de gêneros agrícolas (desde café, passando por laranjas, até mesmo produtos básicos e o desperdício monumental de gêneros alimentares), tornou-se muito mais difícil aceitar essa tese. Além disso, relacionada à suposição de equilíbrio entre oferta e demanda na agricultura, fica pressuposto também que o nível de composição orgânica no setor agrícola é menor do que no setor industrial, o que cria uma série de implicações teóricas que levaram à uma complexa discussão sobre o modo como o capitalismo penetra no campo. Também hoje, com agricultura high-tech, alimentos transgênicos, colheitadeiras automáticas guiadas por satélite etc., é difícil confiar nessa pressuposição. E mais interessante ainda é que nas próprias reflexões de Marx sobre a industrialização da agricultura (primeiro Livro de 0 Capital), já estavam contidas possibilidades de prever esse desenvolvimento.

David Harvey chama a atenção exatamente para essas especulações de Marx, pouco comentadas. Se a composição de valor na agricultura se torna idêntica à média social ou é maior que a média social - a agricultura se tornaria tecnologicamente mais avançada, empregando menos trabalho vivo dos que os demais setores produtivos -, então a própria renda absoluta perderia o sentido. Na medida em que a produtividade se ampliaria, as limitações impostas ao avanço do capital na agricultura não poderiam mais 
ser dadas absolutamente pelos proprietários de terra. Os terrenos com produtividade baixa, que lançam suas mercadorias abaixo do preço de mercado, seriam retirados da concorrência e deveriam, por isso, incrementar seus investimentos para superar essa limitação produtiva. $\mathrm{O}$ valor do produto agrícola tenderia a se igualar ao preço de produção ou ficaria abaixo dele, com o que não seria possível despender mais dinheiro sob a forma de renda direta sobre a propriedade. ${ }^{8}$ Nesse caso, é importante destacar que a própria figura aparentemente básica da propriedade fundiária, a renda absoluta, se torna historicamente datada: a tendência do desenvolvimento capitalista na agricultura, em virtude da expansão da produtividade do trabalho, é suprimir a renda em sua forma de restrição monopolista da propriedade da terra.

Tudo que o capital pode fazer é sujeitar a agricultura às condições da produção capitalista. Mas não pode privar a propriedade fundiária de apreender a parte do produto agrícola, da qual só poderia apropriar-se, não por meio de ação direta, mas depois de estabelecida a não existência da propriedade fundiária. Pressuposta essa propriedade, tem o capital, ao contrário, de deixar para o dono da terra o excesso do valor sobre o preço de custo. Essa própria diferença, porém, decorre apenas de diversidade na combinação dos componentes orgânicos do capital. Todas as mercadorias cujo valor, conforme essa composição orgânica, está acima do preço de custo, mostram por isso que são relativamente mais improdutivas que aquelas cujo valor é igual ao preço de custo, e ainda mais que aquelas cujo valor está abaixo do preço de custo, pois exigem quantidade maior de trabalho imediato em relação ao trabalho pretérito contido em capital constante, mais trabalho para pôr em atividade determinado capital. Essa diferença é histórica e pode, portanto, desaparecer. A mesma argumentação que mostra a possibilidade de existir a renda fundiária absoluta , demonstra que está é real, existe na qualidade de mero fato histórico, próprio de certo estádio de desenvolvimento da agricultura, e pode desaparecer em estádio superior (Marx, 1983: 674).

O que temos aqui é que o próprio desenvolvimento da produtividade do valor implica em extinção da renda absoluta. E nesse caso entramos no aspecto fundamental da interpretação de David Harvey sobre a teoria da renda da terra de Marx. Ao contrário de uma teoria da reminiscência de formas de propriedade pré-capitalistas, ${ }^{9}$ uma formulação crítica radical da teoria do capitalismo contemporâneo precisa demonstrar exatamente que a renda da terra é uma categoria da economia política burguesa: a renda precisa ser explicada do ponto de vista da teoria do valor. "O desafio teórico consiste em definir uma teoria coerente da renda da terra dentro da estrutura da própria teoria do valor" (EI: 333; EM: 336; EB: 431). Nesse caso, isso não implica o fim de toda renda fundiária: as condições não são mais dadas pelo caráter monopolista da propriedade da terra, a sua limitação necessária ao avanço da produção, mas pela diferença entre as diversas terras disponíveis. Com a ampliação da composição orgânica, o capital pode não apenas escolher as melhores terras disponíveis para investir mas ainda pode alterar sua produtividade de acordo com as inversões que mobilizar para a propriedade imobiliária. Isso significa que a propriedade fundiária deixa de ser um limite com qual o capital precisa negociar e se transforma num elemento mediado, mobilizado, produzido pelo próprio capital. A diferença entre as propriedades continua a valer e se amplia pelos próprios investimentos, produzindo lucro extra de acordo com esses diferenciais - o que leva ao pagamento de renda para seus proprietários na proporção em que os terrenos oferecem um valor abaixo do preço de mercado. 


\section{Teoria do valor e propriedade imobiliária}

16 Pareceria um projeto fadado ao fracasso querer demonstrar os vínculos entre teoria do valor e teoria da renda fundiária se a definição básica de renda é aquela que ignora o trabalho como fonte da apropriação da riqueza socialmente produzida - a propriedade privada da terra permite vendê-la independente de ser um produto do trabalho, portanto, a terra possui preço, mas não valor. ${ }^{10}$

Contudo, o capitalismo não é apropriação da riqueza a partir do trabalho, mas apropriação da riqueza produzida pelo trabalho, uma apropriação (distribuição) que pode ocorrer por uma série de critérios: a contribuição para a produção com trabalho propriamente dito salário -, a contribuição para a produção com meios de produção - lucro - e a contribuição com a base física da produção, a terra - renda.

Entretanto, com o desenvolvimento da produtividade agrícola, a renda absoluta pode ser eliminada com a igualação do valor do produto agrícola com seus preços de mercado, o que elimina a extração da renda por parte dos proprietários apenas pelo fato de possuírem a propriedade. A única maneira presente ainda de extrair renda é através da produção num valor abaixo do preço de mercado, aquele estabelecido pela média dos demais produtores. É preciso conseguir uma ampliação da produtividade acima da dos concorrentes para se obter um ganho extra, que pode ser convertido, por isso, em renda diferencial. ${ }^{11}$ Mas como se consegue uma produtividade extra? No caso da agricultura, pelo uso de terrenos mais férteis, o que pode ser obtido tanto pela fertilidade natural dos terrenos ou pelo investimento em insumos agrícolas, adubos orgânicos ou químicos. Ora, é claro que há uma diferença grande entre as duas estratégias e aqui conta novamente o contexto histórico da teoria da renda: uma terra naturalmente fértil significa ganhos de produtividade gratuitos, mas uma terra cuja fertilidade é obtida através de uma série de inversões em fertilizantes precisa da amortização desses investimentos. Ou seja, a diferença entre terrenos se deve ao próprio capital, não mais à natureza, o que nos faz pensar que, conforme avança as relações capitalistas e a industrialização em todos os planos, inclusive na agricultura, a superação dos limites naturais da produção, a criação de uma natureza artificializada, as fronteiras entre a fertilidade natural e a fertilidade artificial ficam apagadas. No caso das cidades, o mesmo pode ocorrer para as bases físicas da edificação: as diferenças naturais entre terrenos são cada vez menos importantes para um empreendimento, na medida em que é possível alterar radicalmente a drenagem, declive etc. através dos investimentos e preparação prévia para a construção.

O mesmo se repete em função da localização - e aqui tanto faz se campo ou cidade. A localização de um imóvel depende menos de condições dadas, naturais, e mais dos investimentos públicos e privados em meios de transporte, acesso, desenvolvimento regional, oferta de serviços em sua vizinhança etc. Assim, mais do que no caso das condições naturais da base física do imóvel, a localização é primordialmente uma localização relativa, que muda conforme o desenvolvimento dos vínculos entre a propriedade e seu entorno imediato, próximo ou mais distante. Em parte decorrente dos investimentos públicos em infraestrutura e, portanto, de alguma maneira não diretamente controlável pelas empresas (fazendo abstração aqui de todo o lobby e pressão política que as corporações e proprietários exercem diante do Estado), a melhora da localização pode resultar de investimentos dos proprietários dos terrenos, reorganizando 
sua logística, melhorando a infraestrutura nas proximidades e investindo em meios de transporte mais rápidos e eficientes.

Essa reflexão sobre a diferença de renda que pode ser obtida em virtude de uma qualidade distinta oferecida pela propriedade imobiliária - seja suas características físicas, seja sua relação com as demais propriedades (localização) -, nos leva a considerar cada vez mais os recursos mobilizados na produção dessas características diferenciadas, portanto, não mais como algo dado, natural e gratuito. A reflexão aponta cada vez mais para um amálgama entre renda e capital. A recriação por parte do capital das condições que antes eram específicas a determinados lugares, naturalmente, são uma demonstração da historicidade da categoria da renda:

O capital cria em um lugar as condições de produção que são dons gratuitos da natureza em outra parte. $O$ limiar entre os juros sobre o capital e a renda sobre a terra parece algo turvo até que se amortiza o investimento, quando qualquer melhora permanente se converte em um bem gratuito e, portanto, em princípio não diferente dos dons gratuitos da natureza. "A produtividade da terra engendrada assim pelo capital coincide posteriormente com sua produtividade 'natural' e nesta forma aumenta a renda". Sobre estas bases, Marx refuta a opinião de Ricardo de que a renda é um pagamento pelas "forças originais e indestrutíveis da terra", porque estas forças são produto da história tanto como da natureza. (Harvey, EI: 337; EM: 340; EB: 435).

Aqui as relações capitalistas se estreitam de tal maneira que já não é possível mais determinar a origem da renda diferencial como dada pelas disparidades naturais. Marx anteviu essa possibilidade, mas ainda afastando como um além histórico indeterminado. ${ }^{12}$ Mas o que era mera especulação naquele momento se tornou realidade hoje - se não para o campo, sem dúvida para as grandes cidades e metrópoles onde a fronteira urbana encontra seus limites de expansão e faz-se cada vez mais necessário o "redesenvolvimento" de antigas áreas, isto é, o "desenvolvimento desigual" (Neil Smith) levado ao extremo na forma da produção relativa de espaço.

As determinações geográficas são fundamentais para entender como, através da produção de espaço, é possível mesclar propriedade e capital. E como realidade atual, os investimentos capitalistas na propriedade são cada vez mais formas de se obter ganhos na concorrência, reduzir custos, oferecer infraestrutura mais adequada ou, no limite - e nesse caso a categoria renda continua fácil de determinar - algo sem igual que justifique a extração de uma renda de monopólio. Como investimentos, as melhorias precisam ser amortizadas, são custos na produção do espaço geográfico, não são dádivas naturais. Se são elementos de um arrendamento, então vão compor a totalidade cedida em aluguel, portanto, podem ser considerados também objetos de empréstimo, do qual não apenas se pode deduzir a amortização (restituição do capital investido em sua produção) mas podem permitir seu proprietário auferir juros.

Melhorias incorporadas na terra são, com certeza, o resultado do trabalho humano. Casas, lojas, fábricas, rodovias etc. são produzidas como mercadorias e, portanto, podem ser tratadas como valores em curso na circulação através do ambiente construído. Um componente da renda pode ser tratado então como um caso especial de juros sobre o capital fixo ou o fundo de consumo. A parte da renda que nos põe dificuldades é o pagamento puro da terra somente, independente das melhorias feitas nela. (EI: 330-331, EM: 333-334; EB: 428).

Nesse caso, para o proprietário do imóvel, sua benfeitoria, imobilizada na propriedade, pode muito bem passar a render ganhos gratuitamente após a amortização, se continuar a ser utilizada. Aqui vale a mesma coisa para o capital fixo que, resistindo por vários 
períodos produtivos de uma empresa, continua sendo útil mesmo depois de sua amortização - os preços das mercadorias com ele produzidas podem cair ou render um ganho extra, já que não é preciso mais despender custos em seu pagamento. ${ }^{13}$

Tudo isso nos leva a crer que o desenvolvimento capitalista torna caduca a figura classista do proprietário fundiário. Isso não significa de modo algum que ele seja eliminado - esse foi o projeto e a reinvindicação dos burgueses radicais, que queriam eliminar toda forma de renda como ganho sem base produtiva. Não se trata disso. 0 que verificamos é que a posição de classe dos proprietários de terras fica em xeque assim que sua forma de inclusão no processo de produção capitalista se deve mais ao investimento de capital propriamente dito do que a algo previamente estabelecido pelas condições naturais. Também sua forma de rendimento, isto é, sua participação na distribuição do produto social deixa de ser uma categoria específica e se confunde cada vez mais com o lucro ou o juro propriamente dito. Se o rigor da definição marxiana de classe se prende às diferenças de posição nas esferas da produção e da distribuição capitalistas ${ }^{14}$, então o proprietário fundiário não passa de uma fração da própria classe burguesa, tal como o capitalista comerciante ou capitalista rentista.

As considerações históricas não podem ser ignoradas aqui e o exemplo da Inglaterra para Marx são determinantes para sua definição de proprietário fundiário como uma classe singular. ${ }^{15}$ Sem dúvida a manutenção da renda absoluta em determinado período da história burguesa e em determinados continentes, países e regiões não pode excluir a importância de pensar o caráter particular da estrutura social e interesses da classe fundiária. Para uma teoria crítica do capitalismo, refletir sobre as formas mais desenvolvidas de seu desenvolvimento é o passo inicial, na medida em que essas formas se tornam hegemônicas e ditam as regras que dominam ou submetem as demais formações sociais específicas. Contudo, para uma análise histórica concreta, não é possível dispensar os hábitos, comportamentos e caracteres culturais que estão associados à propriedade imobiliária especificamente. ${ }^{16}$ Por isso não é possível pensar o capitalismo abstraído de seu duelo com formas anteriores - que explicam sobremaneira as diferenças sociais apontadas por Marx entre classes ${ }^{17}-$, nem seu desenvolvimento desigual que constitui elementos internos à sua lógica em contradição com seu núcleo central. ${ }^{18}$

Contudo, o que nos mostra a teoria da renda levada aos seus extremos é que sua lógica funciona cada vez mais "dentro" da estrutura de circulação do capital, portanto, dependente da teoria do valor.

\section{Crédito e renda da terra}

27 Na verdade, não se trata de demostrar que a renda da terra adentrou à circulação do capital. Essa é uma imagem errônea e reproduz a velha interpretação que confere à renda da terra uma forma essencialmente pré-capitalista e que aos poucos é incorporada à sociedade burguesa. Vimos que o grande esforço é mostrar que a teoria da renda é parte integrante da teoria do valor, ainda que aparentemente seja sua negação, já que a terra não é fruto do trabalho, não é resultado de uma abstração socialmente objetivada. Contudo, como o preço na sociedade burguesa é o resultado da determinação do valor das mercadorias em dinheiro - portanto representação particular do valor das mercadorias por meio do equivalente universal -, então a única maneira de um objeto qualquer se tornar objeto de compra e venda é passar pelo sistema de preços. A renda sobre o monopólio da terra propriamente dita e os investimentos de capital imobilizados no 
imóvel têm que passar necessariamente pelo sistema monetário - devem ganhar a forma de preços, ser convertidos em dinheiro. Ambos, não importando sua origem, são identificados no processo de transformação das mercadorias em unidades de riqueza quantificáveis, ou seja, são submetidos ao padrão de preços. ${ }^{19}$

Isso ainda não facilita em nada a tentativa de integrar a teoria da renda numa teoria do valor, pois o fazemos obliquamente através do preço. Contudo, há uma maneira mais adequada de demonstrar a vinculação da propriedade imobiliária às raízes mesmas da sociedade capitalista e o seu caráter especificamente burguês.

Comecemos pelo exemplo inicial dado por Marx, ainda na primeira seção de 0 Capital, portanto, antes mesmo de tratar da forma capital. Expondo as contradições internas da mercadoria, Marx desenvolve a forma dinheiro e, desenvolvendo suas funções, aponta como o dinheiro pode servir como meio de pagamento. O exemplo que usa, para isso, é singular:

Uma classe de mercadorias requer mais, outra menos, tempo para ser produzida. A produção de diversas mercadorias depende das diversas estações do ano. Uma mercadoria nasce no lugar de seu mercado, outra tem de viajar para um mercado distante. Assim, um possuidor de mercadorias pode apresentar-se como vendedor antes que outro como comprador. Com constante repetição das mesmas transações entre as mesmas pessoas, as condições de venda das mercadorias se regulam pelas suas condições de produção. Por outro lado, vende-se o uso de certas classes de mercadorias, por exemplo, uma casa, por determinado espaço de tempo. Somente após o decurso do prazo fixado recebe o comprador realmente o valor de uso da mercadoria. Ele a compra, portanto, antes de pagá-la. Um possuidor de mercadorias vende mercadorias que já existem, o outro compra como simples representante do dinheiro ou como representante de dinheiro futuro. $O$ vendedor torna-se credor, o comprador, devedor. Com a metamorfose da mercadoria ou o desenvolvimento de sua forma valor se altera aqui, o dinheiro assume outra função. Converte-se em meio de pagamento (Marx, 1985: 114).

30 A casa é um exemplo de mercadoria que interrompe o vínculo imediato entre momento de venda (M-D) e momento da compra (D-M), postergando o pagamento da mercadoria e introduzindo a função da moeda de crédito na circulação de mercadorias. Essa formulação nos lança numa série de questões importantes para compreender a sociedade capitalista. A observação inicial a ser feita é que, ao servir como meio de pagamento, o dinheiro cria a instituição social do crédito, produz as formas de empréstimos possíveis para diversas relações econômicas, funciona agora como uma mercadoria especial - dinheiromercadoria - e inclusive induz à criação de dinheiro de crédito (uma forma alternativa de medida de valor). A teoria da renda, por exemplo, seria impensável sem esse sistema de crédito gerado pela função como meio de pagamento do dinheiro - assim como a circulação do capital fixo, a rotação da produção, o adiantamento de salários, o capital a juros etc. Essas formas desdobradas da sociedade capitalista, como salienta em vários momentos David Harvey, não apenas invocam mas necessitam do sistema de crédito para que se desenvolvam. Portanto, a renda da terra só pode ser compreendida no contexto de uma sociedade que é mediada por mercadorias e dinheiro, uma sociedade que desenvolveu de tal maneira as funções do dinheiro que ergueu um sistema de crédito, uma economia monetária propriamente dita. ${ }^{20}$

31 O exemplo da casa é particularmente significativo porque remete a uma classe de mercadorias que exige tempo para a sua produção e circulação. Uma casa, um edifício, uma loja ou uma estrutura industrial exigem um dispêndio longo de tempo para serem produzidos e por isso, como qualquer mercadoria que têm seu valor determinado pelo 
tempo de produção, tem valor elevado. Exige-se um grande investimento de capital num prazo longo, sem que esse capital possa rapidamente retornar e lucrar. É preciso também um longo prazo para que os investimentos sejam cobertos. Isso cria, desde o princípio, a necessidade da antecipação dos investimentos almejando sua futura realização, seu retorno numa forma maior de recursos. Dado que esse tipo de investimento exige um gasto constante e duradouro de capital, é preciso adiantar capital para que sua produção seja garantida. A única maneira de fazer isso, a não ser que os próprios construtores tenham uma grande soma de capital disponível para usar sem a pressão do retorno em curto ou médio prazo, é contrair empréstimos com a garantia futura da venda ou aluguel dos imóveis. É certo que todo adiantamento de capital exige não apenas o retorno do montante emprestado, mas também um acréscimo na forma de juros. $E$ aqui novamente nos encontramos na teia complexa que enreda capital e renda.

o que se faz, desse ponto de vista, é simplesmente vender a mercadoria antes mesmo de sua produção, quando se oferece aos possíveis usuários dos imóveis o pagamento repartido no tempo de sua futura propriedade (em prestações). $O$ caso aqui é que as mercadorias imobiliárias, como são particularmente específicas pois seu tempo de produção e de circulação são longos ${ }^{21}$ são também bases para obtenção tanto de lucros quanto de juros. Os lucros derivam, principalmente para os construtores, da exploração do trabalho de produção desses imóveis. Os juros surgem em decorrência da mobilização de recursos monetários para os construtores e, portanto, dedução dos lucros dos construtores. Aqui confluem capital produtivo e capital a juros. Mas além dessas duas formas de capital comparece também a propriedade fundiária.

Se o edifício será construído, seu imóvel representa um custo para a produção ou a sua localização poderá render ganhos adicionais - participam da circulação monetária e dos ciclos de capital no ambiente construído tanto as formas de lucro, de juros quanto a de renda. E no fundo é quase impossível dissociar juros de renda nesse caso - assim como já era difícil dissociar a renda do lucro, no caso dos investimentos em estrutura dos imóveis.

Se o capital a juros consiste no adiantamento de recursos monetários (empréstimo) visando a dedução dos lucros futuros, a renda da terra aparece como um adiantamento estabelecido para que futuramente aquela propriedade possa ser utilizada. Na verdade, dado que a renda é determinada pelo potencial das características intrínsecas da propriedade, seja suas qualidades físicas ou sua localização, então a renda nada mais é do que capital a juros na forma especulativa mais precisa de todas, isto é, o adiantamento de ganhos futuros. É a especulação que vemos aqui no sentido original do termo acompanhar ao longo do tempo, observar o movimento. É a categoria do tempo que remete aqui à singularidade rentista dessa forma de propriedade. A propriedade da terra poderia, por isso, ser descrita nos termos mais adequados como uma forma de capital a juros. Melhor dizendo: já que remete à antecipação de ganhos de longo prazo, que podem vir a ser produzidos ou nunca ser realizados, a propriedade da terra é a base mesma do capital fictício - a materialização monetária no presente de recursos, valores, que sequer existem ainda, amparado apenas na expectativa de sua realização futura. $O$ vínculo entre renda e teoria do valor novamente se estabelece, ainda que por via negativa: a propriedade se torna uma garantia (frágil e instável) de obter futuramente a produção de valor nos limites daquela terra.

Para o comprador, a renda figura em seus livros de contabilidade como os juros sobre o dinheiro desembolsado na compra da terra e em princípio não difere de investimentos similares em dívida do governo, ações e bônus de empresas, dívida do consumidor etc. $\mathrm{O}$ dinheiro desembolsado é capital a juros em todos os casos. A 
terra se torna uma forma de capital fictício e o mercado de terras funciona simplesmente como um ramo particular - ainda que com algumas características especiais - de circulação do capital a juros. Sob essas condições a terra é tratada como um puro bem financeiro que se compra e se vende segundo a renda que produz. Como todas as demais formas de capital fictício, o que se compra e se vende é um direito a um rendimento futuro, o que significa um direito sobre benefícios futuros pelo uso da terra ou, mais diretamente, um direito ao trabalho futuro (EI: 347; EM: 350; EB: 447-448).

E aqui estamos ainda no nível mais básico desse sistema, em que para dar início à obra é preciso adiantar para os proprietários a renda fundada na expectativa de um futuro uso da construção a ser erguida na propriedade. Na medida em que o monopólio da terra oferece limites à atuação do capital da construção, então os próprios títulos de propriedade se tornam objetos de mobilização no mercado. A intermediação financeira atinge mesmo os títulos de propriedade ampliando a lógica da circulação monetária: ao adquirir a propriedade para construir um edifício de apartamentos, por exemplo, uma empreiteira pode simplesmente, durante o processo mesmo de produção, repassar os títulos de propriedade das futuras residências para uma instituição bancária que ficará a cargo de oferecê-los no mercado. A propriedade não apenas circula rapidamente nesse caso, sendo fracionada na medida mesmo de sua ampliação (fração ideal), como pode ainda servir novamente como meio de adiantamento de recursos e de obtenção de juros por exemplo, se o banco vende os apartamentos através de financiamento de longo prazo para os futuros proprietários. Por sua vez, essas cartas de financiamento imobiliário podem ser convertidas em títulos financeiros se transformadas em dinheiro de crédito, ativos num mercado secundário. ${ }^{22}$ Essa duplicação complexifica e torna indissociáveis as várias formas de rendimento envolvidas na produção imobiliária - renda, juros e lucro. É possível mesmo ainda que os títulos de propriedade sejam mantidos em espera de futura capitalização, aguardando uma modificação, por exemplo, nas condições externas do imóvel - se o Estado investir em serviços públicos, infraestrutura ou mesmo se empreendimentos privados favoráveis forem erguidos na vizinhança, então a renda diferencial se elevará. Na prática, a complexa configuração alcançada pelo sistema monetário com a financeirização, isto é, a intermediação de capital a juros, impede o isolamento das formas de capital envolvidas e mesmo dos resultados monetários obtidos os variados rendimentos.

Por esta razão, a produção e a manutenção dos ambientes construídos, frequentemente se cristaliza em um sistema altamente especializado que enlaça agentes econômicos que realizam cada papel separadamente ou em combinação limitadas.

Como funciona esse sistema não pode ser entendido sem invocar os elementos da distribuição, tais como renda, juros e impostos. A renda é a base do preço da terra e opera alocando capital e trabalho na terra, orienta a localização da produção, troca e consumo futuros, fixa a divisão geográfica do trabalho e a organização espacial da reprodução social. Isto se aplica unicamente na medida em que a terra se converte em uma forma pura de capital fictício. Os títulos de propriedade da terra devem ser trocados livremente como um bem financeiro puro. A renda é então assimilada a uma forma de juros que se identifica especialmente com os atributos da localização. O capital-dinheiro, por sua parte, também pode se converter em um valor de uso material e funcionar como tal em troca de um pagamento por juros. Portanto, o capital a juros pode circular diretamente através do ambiente construído, os rendimentos que são gerados assim podem ser capitalizados e os títulos de propriedade podem ser trocados. O Estado pode também facilitar a circulação de capital no ambiente construído emitindo bônus contra receitas fiscais futuras. Estes 
últimos podem ser capitalizados e convertidos em formas de capital fictício (EI:

395-396; EM: 398-399; EB: 503-504). terra é, em certo sentido, a forma ubíqua desta. Ao desenvolver-se e mostrar sua natureza necessariamente amalgamada com as formas do capital (lucro, juros etc.), ao tornar-se onipresente em função da expansão das fronteiras imobiliárias mas também devido à capilaridade do mercado de terras no campo e na cidade, ao vulgarizar-se no dia-a-dia da sociedade capitalista, a renda da terra se tornou quase invisível. Fazendo-se comum e familiar, no sentido de que se banalizou pelo cotidiano, seus nexos intrínsecos ganharam uma transparência que torna difícil sua compreensão. Apesar de todos os limites e toda a exclusão gerada pela propriedade privada da terra e das construções, o mercado imobiliário se alastrou de tal maneira que fugiu ao foco teórico. A generalidade do mercado imobiliário não significou, ao contrário do que pensa o dogmatismo liberal, uma facilitação do acesso à terra. Pelo contrário: quanto mais universalizadas e intensas as práticas do mercado imobiliário, mais exclusões cria à sua volta - os milhões despejadas nos EUA e o crescente mercado informal das favelas cariocas deveriam servir de comprovação para isso. Mas é aqui exatamente que, paradoxalmente, o véu de transparência encobre os processos mais profundos. O familiar, como ensina a boa herança hegeliana, é exatamente o não-conhecido, porque imediato - não passou por mediação teórica, não é elaborado pela reflexão.

A história atual nos revela o quanto a terra deixou de ser um bem com limitações devido à sua natureza particular e passou, através do desenvolvimento capitalista - seja a expansão de sua produção quanto a ampliação de sua circulação -, a um bem financeiro, cujo mercado se estendeu vertiginosamente. enraizada na forma mercantil da terra se encontra essa forma social. Entretanto, isso não deve ser encarado apenas como uma forma evoluída da natureza capitalista. A explosão dos mercados imobiliários e sua entrada no centro mesmo dos interesses econômicos mundiais - quantas bolhas imobiliárias vimos crescer e estourar nos últimos vinte anos? não são apenas o resultado da forma mais avançada obtida pelo capitalismo, são o indício também dos limites de seu desenvolvimento.

O fato de que a renda da terra tenha se imiscuído de tal forma nos negócios que até mesmo instituições públicas hoje se tornem promotoras ou corretoras imobiliárias deve ser visto como o sinal de que as condições internas para a reprodução capitalista estão enfrentando dificuldades monumentais. A crise estrutural do capitalismo, resultado de uma série de processos complexos, é uma crise da produção de valor. A enorme produtividade capitalista não apenas reduziu ao mínimo o tempo de trabalho presente 
nas mercadorias, impedindo assim o acréscimo periódico de uma massa de valor nova capaz de fazer o sistema se reproduzir ampliadamente, como ainda dispensa aos borbotões milhões de trabalhadores, em todo o mundo, do processo de produção. A dificuldade de criar no "aqui e agora" da dinâmica capitalista a energia capaz de fazer funcionar essa sociedade têm como consequência a antecipação cada vez mais intensa de presumidos ganhos futuros. A utilização ficcionalizada no presente de uma massa monetária gigantesca, lastreada em nada além do que a almejada ilusão de sua produção futura, tem por objetivo compensar os danos provocados à produção de valor.

41 A especulação financeira e, no centro dela, a capitalização baseada na propriedade imobiliária, não deve ser vista meramente como uma forma sofisticada que o capitalismo encontra para sobreviver, como uma ferramenta entre outras de formação e resolução de crises. ${ }^{23}$ As crises constantes, cada vez mais comuns, de frequência acelerada e de destruição amplificadas não podem nos levar à conclusão fácil de que o próprio sistema de produção imobiliária contribui para a solução das crises. Há algo mais grave aí e que precisa ser teoricamente enfrentado: a mistura das formas de capital não significa uma sofisticação de ferramentas para os novos tempos. A produtividade necessária à manutenção do sistema (geração de lucro) cada vez mais é substituída por formas improdutivas, simulação de riqueza (juros e renda). ${ }^{24} \mathrm{~A}$ ilusão de que isso possa ser uma forma nova de reprodução capitalista não revela apenas um mecanismo de afastamento subjetivo dos perigos sociais, mas principalmente uma incompreensão teórica dos fundamentos do capitalismo. A grande contribuição que podemos obter a partir da obra de David Harvey - hesitante em seus próprios textos - é de que a falta de produção real de valor exige essas medidas fictícias paliativas, mas essa alternativa em si mesma não é alternativa nenhuma. Os limites do capital estão claros em virtude da transformação que fez de sua base social - a propriedade da terra - em meio primordial de especulação. Em grande medida, o que vemos hoje não é exatamente que "a urbanização é tão decisiva para a acumulação do capital" (Harvey, 2013b: 171), mas que a produção e reestruturação urbanas se tornaram fundamentais para a reprodução simulada do capital. 0 incremento desproporcional do capital que rende juros desprovido de substância real - trabalho e valor - representa a afirmação das formas fictícias de reprodução (capitalização). ${ }^{25} \mathrm{O}$ resultado socialmente destrutivo disso é óbvio, mas ainda assim por todos os lados vemos elogios à dinâmica do mercado imobiliário.

O que é mais significativo em todo o processo desenfreado e generalizado de especulação imobiliária - Neil Smith não por acaso fala de uma terceira fase do processo de elitização de bairros centrais como "gentrificação generalizada" (2006) - é a ilusão que se constrói em torno da capacidade desses ambientes urbanos. Todos os elogios inconsequentes às transformações em nossas paisagens urbanas, principalmente entre os cariocas, o palavreado sobre a "vitalidade" de nossas cidades, o dinamismo urbano etc. não passam de apologia superficial que é incapaz de perceber os nexos estruturais mais profundos entre produção imobiliária e ficcionalização da riqueza. A aparência bastante concreta da série infindável de prédios, monumentos e museus de grife não é termômetro de coisa alguma, a não ser da complexa relação entre fluidez do capital e incorporação imobiliária. Quem confia irrefletidamente que virtuose imobiliária pode ser sintoma de uma solidez econômica nas condições do capitalismo do século XXI é porque não consegue enxergar as mudanças fundamentais na economia mundial e se rende ao ilusionismo das estruturas de metal, concreto e vidro que são tão sólidas quanto a próxima rodada altista nas bolsas. Deixar-se convencer por essa paisagem em mutação tão facilmente é render-se ao 
capitalismo de fachada high-tech e financeirizado. Talvez nem tanto: em certo sentido, essa miragem é apenas uma forma mais atual daquela visão tão combatida por Marx que enxergava na própria terra, em si mesma, a fonte do valor, não entendendo o contexto formal em que esse tipo de propriedade gerava a apropriação de parte da riqueza sob condições capitalistas. A prisão do entendimento no conteúdo material impede seu reconhecimento dos nexos formais da socialização. Aquilo que é, à primeira vista, o concreto, torna-se na verdade uma mera impressão não-mediada, portanto, falsa em sua pretensão de sê-lo.

É fato que no Brasil esse comportamento talvez seja justificado em função do mercado imobiliário brasileiro ser tradicionalmente caracterizado por um imobilismo. Assim, ruas esburacadas, canteiros de obras espalhados, guindastes dominando a paisagem são facilmente interpretados como "mercado aquecido". Contudo, isso deveria ser enfrentado teoricamente e não abraçado simplesmente sem reflexão. Que grande parte da intelectualidade se renda à "exploração crescente do espaço nas grandes cidades" (Jameson, 2002: 179) como modelo de desenvolvimento econômico, revela não apenas a incapacidade teórica de refletir profundamente sobre a sociedade burguesa, mas também os fundamentos "científicos" da esquerda. Essa esquerda que se rendeu ao "realismo econômico" se deixa guiar não apenas pelas "máscaras de caráter do capital" mas anda de mãos dadas com o capital fictício.

\section{BIBLIOGRAPHY}

Botelho, Maurilio Lima. Teoria da Crise em David Harvey. In: Revista Continentes (UFRRJ), ano 3, n.4, 2014, p. 66-111. Disponível em: http://r1.ufrrj.br/revistaconti/pdfs/4/ART4.pdf. Acesso em nov. 2014.

Dinheiro e crédito em David Harvey: comentários críticos. In: Espaço e Economia, n. 6, 2015. Disponível em: http://espacoeconomia.revues.org/1760. Acesso em set. 2015.

Fausto, Ruy. Marx: lógica e política. Investigações para uma reconstituição do sentido da dialética. Tomo II. São Paulo: Brasiliense, 1987.

Harvey, David. Los limites del capitalismo y la teoria marxista. Cidade do México: Fondo de Cultura Económica, 1990.

. Do administrativismo ao empreendedorismo: a transformação da governança urbana no capitalismo tardio. In: A Produção Capitalista do Espaço. São Paulo: Anneblume, 2005a, p. 163-190.

. A arte da renda: a globalização e transformação da cultura em commodities. In: A Produção Capitalista do Espaço. São Paulo: Anneblume, 2005b, p. 219-239.

The Limits of Capital. London: Verso, 2006

Os limites do capital. São Paulo: Boitempo, 2013a.

--------_. Ciudades rebeldes. Del derecho a la ciudad a la revolución urbana. Madrid: Akal, $2013 b$. 
Jameson, Fredric. A cultura do dinheiro: ensaios sobre a globalização. Petrópolis: Vozes, 2002.

Kurz, Robert. A ascensão do dinheiro aos céus. Disponível em: http://obeco.planetaclix.pt/ rkurz101.htm. Acesso em set. 2015.

Marx, Karl. Teorias da Mais-Valia: História Crítica do Pensamento Econômico, vol. II. São Paulo: DIFEL, 1983.

o Capital - crítica da economia política. Livro I: O processo de produção do capital (tomo I) São Paulo: Nova Cultural, 1985a.

o Capital - crítica da economia política. Livro I: O processo de produção do capital (tomo II) São Paulo: Nova Cultural, 1985b.

O Capital - crítica da economia política. Livro III: O processo global da produção capitalista (tomo V) São Paulo: Nova Cultural, 1986.

O 18 Brumário e Cartas a Kugelmann. São Paulo: Paz e Terra, 1997.

Possas, Mario Luiz. Dinâmica e concorrência capitalista - uma interpretação a partir de Marx. São Paulo: Hucitec, 1989.

Smith, Neil. The new urban frontier: gentrification and the revanchist city. Nova York: Routledge, 1996.

. A gentrificação generalizada: de uma anomalia local à "regeneração" urbana como estratégia urbana global. In: Bidou-Zachariasen, C. (org.). De volta à cidade. Dos processos de gentrificação às políticas de "revitalização" dos centros urbanos. São Paulo: Annablume, 2006, p. 59-87.

Wheen, Francis. O Capital de Marx [Uma biografia]. Rio de Janeiro: Zahar, 2007.

\section{NOTES}

1. E no caso do Brasil hoje fica mais evidente o quanto a teoria da renda da terra, mesmo desenvolvida no campo da esquerda, servia na maioria das vezes como teoria modernizadora, contra o domínio do latifúndio porque este impunha restrições ao desenvolvimento capitalista.

2. Utilizaremos a segunda edição inglesa (2006) de Os Limites do Capital como a base para a tradução dos trechos aqui citados. Faremos referência também às páginas da edição mexicana (1990) e da edição brasileira (2013a), mas a tradução desta é problemática e torna o texto incompreensível. A referência a todas essas edições utiliza a seguinte nomenclatura nas citações: EI - edição inglesa; EM - edição mexicana e EB - edição brasileira, sempre seguida das páginas.

3. Ver quanto a isso o importante capítulo 25 de 0 Capital sobre a "moderna teoria da colonização" (Marx, 1985: 295-302).

4. “(...) renda é o preço pago ao dono de forças naturais ou de meros produtos da natureza pelo direito de usar aquelas forças ou de apropriar-se (pelo trabalho) daqueles produtos. Esta é na verdade a forma em que toda renda (rent) aparece na origem". (Marx, 1983: 677).

5. No Brasil é mais comum falarmos em "renda do solo" urbano e "renda da terra" para o caso rural. Essa diferente tradução não deixa de ter inconvenientes - em certo sentido, no campo interessa mais o solo do que a mera superfície. Mas mesmo na cidade as propriedades do solo não são indiferentes: “A agricultura é sensível, geralmente falando, à fertilidade e à localização conjuntamente, enquanto as fábricas, casas, lojas etc. são sensíveis principalmente à localização. Entretanto, as qualidades do terreno - drenagem, inclinação, aspecto, salubridade etc. - não são alheias à localização deste último, enquanto que certos tipos de agricultura industrializada quase não dependem da produtividade natural da terra que ocupa" (Harvey, EI: 341; EM: 344; EB: 440). 
6. “(...) a força natural não é a fonte do sobrelucro, mas apenas a base natural dele, pois é a base natural da força produtiva do trabalho excepcionalmente mais elevada. Assim, o valor de uso é sobretudo portador do valor de troca" (Marx, 1986: 145).

7. Por isso a estratégia cada vez mais comum de, em todas as partes, empregar arquitetos de grife, artistas do aço, concreto e pedra, para erguer monumentos que diferenciam os espaços urbanos. Peter Eisenman em Santiago de Compostela, Frank Gehry em Bilbao, Santiago Calatrava no Rio de Janeiro são alguns dos exemplos recentes em se tentar, através da oferta de um imóvel único (na maioria dos casos um museu, mas pode ser um complexo olímpico, uma casa de cultura, ópera etc.), obter uma renda extraordinária que amplie o preço de seus imóveis e o destino turístico de suas cidades. Sobre isso ver Harvey (2005a e 2005b). Uma interpretação que acompanha o raciocínio de Harvey e se aprofunda na análise estética da arquitetura contemporânea é desenvolvida por Pedro Fiori Arantes (2008 e 2010).

8. "A baixa composição de valor do capital na agricultura pode ser atribuída mais ao atraso tecnológico e científico nesse setor do que qualquer outra coisa. Uma vez que a agricultura se moderniza [catches up], coisa que deve fazer em determinado momento, então a renda absoluta desaparece, deixando os proprietários fundiários que recebem renda sobre o monopólio sem poder fazê-lo". (EI: 352; EM: 355; EB: 454)

9. A tradução brasileira de Os Limites do Capital pode contribuir para uma interpretação totalmente equivocada da obra de Harvey, principalmente no capítulo mais importante, o da renda terra, pois aí "propriedade fundiária" (landed property) é traduzida como "feudalismo" e "proprietário de terras" (landlord) é traduzido como "senhor feudal" ou "feudalista"! Fizemos algumas considerações sobre os problemas nessa tradução em artigo anterior (Botelho, 2014). Não se trata de apenas de erros pontuais, mais de uma teoria inteira sendo perdida pela tradução equivocada.

10. "Mas o que fica então é justamente a questão a resolver: como têm preço coisas que não têm valor e como compatibilizar isso com a teoria geral dos valores". (Marx, 1983: 677).

11. “(..) renda é apenas a diferença entre valor e preço de custo" (Marx, 1983: 699). Preço de custo, nesse caso, é o preço de mercado, não o valor individual, já que Marx está comentando Ricardo e usa sua terminologia. No caso da renda absoluta, o dispêndio de trabalho num terreno ruim implica na venda de produtos acima dos preços de mercado para que a renda seja obtida. É a única exceção à determinação do valor pelo tempo de trabalho socialmente necessário, sem retirar a coerência dessa teoria: em função do caráter monopolista da propriedade da terra, é possível que um tempo de produção acima da média ainda assim seja recompensado socialmente em função da necessidade de sua produção em cobrir à demanda. A expansão e formação de um avançado mercado de terras, como visto acima, elimina essa situação extraordinária e nivela a agricultura a todos os outros ramos da produção. A teoria do valor se aplicará aqui tal como em outros setores.

12. "Se todo o solo cultivável de um país fosse arrendado - pressupondo em geral o modo de produção capitalista e condições normais -, então não haveria solo que não proporcionasse renda, mas poderia haver investimentos de capital, partes isoladas do capital investido no solo, que não proporcionassem nenhuma renda; pois assim que o solo tenha sido arrendado, a propriedade fundiária deixa de atuar como barreira absoluta ao investimento necessário de capital. Continua, no entanto, a atuar como barreira relativa, à medida que a reversão ao proprietário da terra do capital incorporado ao solo traça, para o proprietário, limites bem demarcados. Só nesse caso toda a renda se transformaria em renda diferencial, não em renda diferencial determinada pela diferença de qualidade do solo, mas pela diferença entre os sobrelucros resultantes dos últimos investimentos de capital em determinado solo e a renda que se paga pelo arrendamento do pior solo. A propriedade fundiária só atua de modo absoluto como barreira à medida que condiciona o acesso ao solo em geral, enquanto campo de investimento de capital, ao pagamento de um tributo ao proprietário da terra. Tendo ocorrido esse acesso, o 
proprietário já não pode opor barreiras absolutas ao volume do investimento de capital em dado terreno. A construção de casas em geral encontra uma barreira na propriedade de um terceiro sobre o solo onde a casa deve ser construída. Mas, uma vez "arrendado" esse solo para a construção de casas, depende do arrendatário se construirá uma casa grande ou pequena". (Marx, 1986: 230)

13. Nesse caso, evidentemente, a coerência histórica demandaria a progressiva irrelevância do exemplo: se estamos presumindo o capitalismo altamente desenvolvido, então o nível de concorrência, principalmente a concorrência na redução de custos de produção (o que está implícito no capitalismo monopolista) é tal que o capital fixo rapidamente se inutiliza em virtude das inovações, com o que dificilmente seu uso pode perdurar para além de sua amortização. Como se sabe, a crescente monopolização do capital não reduz a concorrência, só a transfere dos preços para o âmbito dos custos de produção e da transformação estrutural das forças produtivas (Possas, 1989).

14. Somente com a análise da distribuição do mais-valor pode-se realmente ter em conta como as relações de produção se estabelecem como relações de distribuição, mediadas pela propriedade, derivando daí os agentes (Fausto, 1987: 209-214).

15. "O modo de produção capitalista abrange a agricultura de maneira lenta e desigual, como se pode ver na Inglaterra, o país clássico quanto ao modo de produção capitalista na agricultura" (Marx, 1986: 167). É possível que as dificuldades na definição das classes sociais tenham provocado a interrupção da redação definitiva dos demais livros de 0 Capital. Não é um acaso que Marx termine suas anotações justamente no capítulo das classes (capítulo 52). Mas é preciso lembrar que os livros II e III de O Capital são rascunhos organizados por Engels e Marx pretendia se fixar no exemplo do desenvolvimento social russo para escrever sua teoria da renda da terra. 0 biógrafo Francis Wheen nos relata a obsessão de Marx pelas estatísticas fundiárias russas, que o levou a ler montanhas de jornais no original e o afastavam da conclusão da obra, "para grande irritação de Engels, que, segundo confessa, adoraria tocar fogo naquilo tudo" (2007: 45).

16. "Os incentivos sociais para conservar a terra - prestígio, importância simbólica, tradição etc. - também são muito importantes na prática, mas o excluímos aqui de consideração porque não têm raízes diretas no interior de uma teoria pura do modo de produção capitalista" (EI: 367; EM: 370; EB: 471).

17. Em O Dezoito Brumário de Luis Bonaparte, uma importante consideração desses aspectos culturais para definir as classes aparece na oposição entre Orleans, representantes da alta finança, e Bourbons, tradicionais proprietários de terra. Marx opõe as duas famílias e seus lacaios como uma verdadeira oposição entre cidade e campo e acrescenta que as tensões entre ambas se devem à rivalidade entre capital e propriedade da terra, mas também às inimizades, preconceitos, temores, ilusões etc.: "Sobre as diferentes formas de propriedade, sobre as condições sociais, maneiras de pensar e concepções de vida distintas e peculiarmente constituídas. A classe inteira os cria e os forma sobre a base de suas condições materiais e das relações sociais correspondentes" (Marx, 1997: 51). Em meio a essa reflexão, entretanto, Marx enfatiza que suas divergências se devem ao choque de interesses dentro da estrutura capitalista, por isso "falamos em dois interesses da burguesia porque a grande propriedade territorial, apesar de suas tendências feudais e de seu orgulho de raça, tornou-se completamente burguesa com o desenvolvimento da sociedade moderna" (1997: 52).

18. E para isso a teoria de Neil Smith, desenvolvida num diálogo constante com Harvey, assume uma importância fundamental: o capitalismo avança eliminando as fronteiras imobiliárias, incorporando todas terras ao arrendamento, mas deixa também às suas costas imóveis abandonados, estruturas em decadência, terrenos "livres" e bairros inteiros ignorados ao poder público, o que pode criar novos conflitos sociais - ocupação por sem-teto, controle policial, reinvestimento e "gentrificação". A fronteira externa que foi suprimida pela expansão absoluta do capitalismo é recriada internamente por meio de seus espaços relativos (1996). 
19. “O ambiente construído em geral é em parte um bem público e em parte um bem privado e os mercados dos elementos individuais refletem às complexas interações entre as diferentes classes de mercados. Mesmo assim, como os diversos elementos dentro do ambiente construído funcionam como valores de uso localizados, existe a possibilidade de que se ponha uma etiqueta com preço, inclusive depois que seu valor tenha sido devolvido totalmente ao capital. Pode-se obter uma renda por seu uso e capitalizá-la, segundo a taxa de juros que prevalece nesse momento, dentro de um preço de mercado sobre a terra e seus acessórios. Há duas classes de valor de troca que existem então um ao lado da outra: a renda capitalizada sobre elementos antigos e o preço de produção dos novos. Os dois preços são derivados de modo muito diferente, mas ficam reconciliados dentro de uma só estrutura de preços pelo sistema de mercado" (EI: 234; EM: 239; EB: 316-317).

20. "O sistema de crédito estrutura o mercado de terras para preservar a circulação do capital portador de juros como um todo". (EI: 370-371; EM: 373; EB: 475). Sobre isso ver também Harvey (2013b: 66-69). Em outro momento fizemos uma análise e crítica do modo como Harvey desenvolve a teoria do dinheiro e do crédito na sua leitura de Marx. Seria necessário destacar aqui que Harvey, contra suas próprias contribuições mais importantes, considera a economia capitalista uma economia monetária entre outras na história, o que é um equívoco histórico e que produz implicações teóricas. Apontamos que essa leitura problemática se deve à influência do estruturalismo francês (Botelho, 2015).

21. "A relação entre oferta e demanda é assimétrica, porque o tempo de produção e circulação para as residências e edifícios comerciais é muito longo comparado com a da maioria das mercadorias. Aí se fazem cruciais os tempos díspares de produção, circulação e rotação que Marx analisa tão perspicazmente no segundo volume de 0 Capital. Os contratos que financiam a construção são firmados muito antes de que se possam começar as vendas. As diferenças temporais são muito substanciais e isto é particularmente certo para os edifícios comerciais. 0 Empire State Building de Nova York foi inaugurado em 1 de maio de 1931, quase dois anos depois do crack da bolsa e mais de três anos depois do crack imobiliário. As Torres Gêmeas foram planejadas antes mas foram inauguradas depois do crack de 1973 (e durante anos não puderam encontrar compradores privados). A reconstrução do centro de Nova York depois de 11 de setembro está se iniciando quando o valor dos edifícios comerciais está no chão!" (Harvey, 2013b: 78-79).

22. Trata-se aqui do caso do mercado secundário de hipotecas, que veio à tona na crise de 2007/2008. No Brasil, embora a financeirização imobiliária, seja na produção, seja no consumo, tenha sido expandida nos últimos anos, as restrições para a formação de um mercado desse tipo ainda são elevadas.

23. “As reestruturações especulativas obtidas em fases de crédito fácil e de expansão têm que ser racionalizadas no curso das crises seguintes. As ondas de especulação na criação de novas configurações espaciais são tão vitais para a sobrevivência do capitalismo como outras formas de especulação. E dada sua forma, não pode haver dúvida que os processos que temos considerado aqui podem contribuir muito facilmente com a loucura que se manifesta periodicamente dentro do sistema de crédito. A criação de configurações espaciais e a circulação de capital no ambiente construído é, podemos concluir com firmeza, um momento intensamente ativo nos processos gerais de formação e resolução de crises" (EI: 398; EM: 401: EB: 506). Toda a trajetória teórica de Harvey, desde Os Limites do Capital, consiste em trazer o tema das crises para o centro da discussão sobre as configurações geográficas do capitalismo. Contudo, sua abordagem das crises é sempre ambivalente, insistindo com o mesmo peso para as complicações e os atenuantes das crises, ou seja, uma análise que incorre em uma visão do mecanismo capitalista sempre girando em si mesmo, sem uma lógica estrutural de movimento intrínseco que aponta para a eliminação de seus próprios fundamentos - crise estrutural. Veja quanto a isso nossa discussão sobre a sua forma de encarar a crise do capitalismo contemporâneo (Botelho, 2014). 
24. “...uma acumulação de títulos pode aparecer como uma acumulação de capital monetário e tais títulos podem continuar a circular mesmo que não tenham base na produção real” (EI: 287; EM: 291; EB: 378).

25. "A 'condição de possibilidade' do dinheiro se desligar da sua real substância de trabalho é tanto mais forte, quanto maior se torna na reprodução geral a parte que se refere ao capital que rende juros. Quanto a isso, pode de fato constatar-se a longo prazo um desequilíbrio a favor do crédito. A extensão gradual da racionalidade empresarial a toda produção, a sua cientificização e o consequente aumento, em escala secular, da intensidade do capital (ou seja, custos prévios sempre mais altos para uma produção competitiva de mercadorias), além da extensão concomitante do capital acionista anônimo, exigem massas sempre maiores de dinheiro creditício, para poder manter em curso a produção capitalista" (Kurz, 1995).

\section{ABSTRACTS}

O objetivo do presente artigo é enfatizar uma das grandes contribuições da obra de David Harvey - - a teoria da renda da terra - - demonstrando seus vínculos íntimos com a estrutura econômica capitalista e o seu papel nas transformações urbanas contemporâneas. Ressaltando que a renda da terra não pode ser compreendida como herança pré-moderna, nossa reflexão expõe a conexão essencial entre propriedade imobiliária e capital fictício.

The aim of this text is to highlight one the greatest contribution of David Harvey's work - the theory of land rent - presenting the close bonds with the capitalist structure and its roles in current urban changes. Stressing that the value of the land cannot be understood as a premodern heritage; our reflection pictures the vital connection between immovable properties and fictitious capital.

Cet article veut souligner l'une des grandes contributions de la pensée de David Harvey, la théorie de la rente de la terre, afin de démontrer ses liaisions avec la structure économique capitaliste et son rôle dans les transformations urbaines contemporaines. Une fois que la rente de la terre ne peut pas être comprise en tant qu'une héritage pré-moderne, on présente la connexion essentielle entre propriété immobilière et capital fictif.

El propósito de este artículo es resaltar una de las principales contribuciones del geógrafo David Harvey - la teoría de la renta - demostrando su estrecha relación con la estructura económica capitalista y su papel en las transformaciones urbanas contemporáneas. Destacando que la renta de la tierra no puede ser entendida como patrimonio premoderno, nuestra reflexión señala la conexión esencial entre propiedad inmueble y capital ficticio.

\section{INDEX}

Mots-clés: rente de la terre, capital fictif, propriété de la terre, intérêt, developpement urbain Keywords: land rent, fictitious capital, land ownership, interest, urban development Palabras claves: renta de la tierra, capital ficticio, propiedad inmueble, interés, desarrollo urbano

Palavras-chave: renda da terra, propriedade fundiária, juros, desenvolvimento urbano. 
AUTHOR

MAURILIO LIMA BOTELHO

Programa de Pós-Graduação em Geografia da Universidade Federal Rural do Rio de Janeiro

(PPGGEO/UFRRJ). Email: mauralio@oi.com.br 